\title{
Attitudes and Practice of Cervical Cancer Screening among Female University Students from 25 Low, Middle Income and Emerging Economy Countries
}

\author{
Supa Pengpid ${ }^{1,2}$, Karl Peltzer ${ }^{1,3,4 *}$
}

\begin{abstract}
Cervical cancer, the third commonest cancer in women worldwide, can be prevented through early detection by cervical screening (Pap smear). The aim of this study was to investigate the attitudes and practice of cervical cancer screening among female undergraduate university students from 25 low, middle income and emerging economy countries. Using anonymous questionnaires, data were collected from 9,194 female undergraduate university students aged 18-26 years (mean age 20.9, $\mathrm{SD}=\mathbf{2 . 0}$ ) from 26 universities in 25 countries across Asia, Africa and the Americas. Overall, $11.6 \%$ of the female students indicated that they had conducted one or more times a cervical (Pap) smear test; 8.3\% among 18-20 year-olds and $15.6 \%$ among $21-26$ year-old students. There was considerable country variation on having had a cervical (Pap) smear test among 21-26 year-old female university students, ranging from 59.2\% in Colombia and 50.9\% in Barbados to $0 \%$ in India and $1.0 \%$ in Tunesia. Logistic regression showed that cervical cancer screening importance or positive attitude were highly associated with the cervical screening practice. Moreover, risky sexual behaviour and tobacco use, two cervical cancer risk factors, were associated with screening. Cervical cancer screening practices were found to be inadequate and efforts should be made to develop programmes that can increase the uptake of cervical cancer screening.
\end{abstract}

Keywords: Cervical cancer screening - attitude - practice - risk factors - university students - multi-country study

Asian Pac J Cancer Prev, 15 (17), 7235-7239

\section{Introduction}

Cervical cancer is the third most common cancer in women, accounting for $9 \%$ of all female cancers. It is the seventh most common cancer in the world, and is more common in less developed countries-where it accounts for more than $85 \%$ of the global burden of cancer (Globocan, 2012). Cervical screening offers protective benefits and is associated with a reduction in the incidence of invasive cervical cancer and cervical cancer mortality (Peirson et al., 2013). The United States Preventive Services Task Force (USPSTF, 2012) and the American Cancer Society (ACS) recommend that all women should begin cervical cancer screening at age 21 , every three years for women ages 21-65. Several other countries such as Barbados (Pan American Health Organization, 2013) and South Africa (Botha et al., 2010) also recommend to begin cervical cancer screen at the age of 21 , while other countries such as Singapore, Jamaica, Colombia and Venezuela follow the recommendations of the World Health Organization (2013), namely to begin cervical cancer screening with the age of 25 years (Pan American Health Organization, 2013.

Various studies among female university students in low and middle income countries have reported a low participation rate in screening for cervical cancer, e.g., 6\% in Bhutan (Dhendup and Tshering, 2014), 12\% in Ghana (aged 20 to 35 years) (Abotchie and Shokar, 2009), 6\% in Malaysia (Al-Naggar et al., 2010), 0\% to $8.3 \%$ in Nigeria, $0 \%$ (Ayinde et al., 2004; Akujobi et al., 2008; Oladepo et al., 2008; 2009; Aniebue and Aniebue, 2010 ), and $10.7 \%$ among sexually active female students in South Africa (Hoque, 2013). While studies among female university students in high income countries found a higher participation rate in screening for cervical cancer, e.g. $44.8 \%$ in Greece (Bakogianni et al., 2012) and $41 \%$ in USA (Durvasula et al., 2006).

A number of studies have investigated possible reasons for a low participation in cervical cancer screening among female university students, including ignorance of the existence of such a test, ignorance of the importance of screening or lack of risk awareness and the risk factors to the development of cervical cancer, absence of symptoms and lack of awareness of centers where such services are obtainable, and lack of motivation to get screened (Akujobi et al., 2008; Oladepo et al., 2008; 2009; Abotchie and Shokar, 2009; Aniebue and Aniebue, 2010; Ghotbi and

${ }^{1}$ Asean Institute for Health Development, Mahidol University, Salaya, Phutthamonthon, Nakhonpathom, Thailand, ${ }^{2}$ Department of Research Development and Innovation, ${ }^{3}$ Department of Psychology, University of Limpopo, Turfloop Campus, Sovenga, ${ }^{4} \mathrm{HIV} /$ AIDS/STIs/and TB (HAST) Research Programme, Human Sciences Research Council, Private Bag, Pretoria, South Africa *For correspondence: karl.pel@mahidol.ac.th 
Anai, 2012; Oshima and Maezawa, 2013). Risk factors for cervical cancer include genital, syphilis/gonorrhoea history, multiple sexual partners and intercourse at an early age, chemical, dietary and life factors, cigarette smoking, barrier and oral contraceptives and poor personal hygiene (Chou 1991; Murthy and Mathew, 2000).

The aim of this study was to investigate the attitude and practice of cervical cancer screening among female university students from low, middle income and emerging economy countries.

\section{Materials and Methods}

\section{Sample and procedure}

This cross-sectional study was carried out with a network of collaborators in participating countries (see Acknowledgments). The anonymous, self-administered questionnaire used for data collection was developed in English, then translated and back-translated into languages (Arabic, Bahasa, Chinese, French, Lao, Russian, Spanish, Thai, Turkish) of the participating countries. The study was initiated through personal, academic contacts of the principal investigators. These collaborators arranged for data to be collected from 400 male and 400 female undergraduate university students aged 16-30 years by trained research assistants in 2013 in 1 or 2 universities in their respective countries. The universities involved were located in the capital cities or other major cities in the participating countries. Research assistants working in the participating universities asked classes of undergraduate students to complete the questionnaire at the end of a teaching class. Classes were recruited according to timetable scheduling in a quasi-random pattern. We included no incentive for participation, and there were no penalties for refusing to complete the survey. The students who completed the survey varied in the number of years for which they had attended the university. A variety of majors were involved, including education, humanities and arts, social sciences, business and law, science, engineering, manufacturing and construction, agriculture, health and welfare and services. Informed consent was obtained from participating students, and the study was conducted in 2013. Participation rates were in most countries over $90 \%$. Ethics approvals were obtained from all participating institutions.

\section{Measures}

Cervical cancer screening practice and attitude: Women were asked, "How long has it been since you had a cervical (Pap) smear test? Response options ranged from $1=$ never to $4=$ more than 3 years. Further, they were asked about how important it is "For women to have a regular cervical smear test." Response options ranged from $1=$ of very low importance to $10=$ of very high importance (Wardle and Steptoe, 1991).

Sexual variables: the 'number of sexual partners in the past 12 months' was determined by the response to the question: 'How many sexual partners have you had in the past 12 months?' The variable was dichotomised into 0 or 1 and 2 or more partners. Further, participants were asked, "During the past 3 months did you use a condom with your primary partner?" Response options ranged from $1=$ never to 5=Every time; "every time" was defined as "consistent" condom use. Finally, female students responded to the question, "Have you ever been diagnosed with a sexually transmitted infection?"

Tobacco use was assessed with the question: Do you currently use one or more of the following tobacco products (cigarettes, snuff, chewing tobacco, cigars, etc.)? Response options were "yes" or "no" (World Health Organization, 2008).

Socio-demographic questions included age, gender, marital status, and socioeconomic background was assessed by asking survey participants to rate their family background as wealthy (within the highest $25 \%$ in their "country", in terms of wealth), quite well off (within the $50 \%$ to $75 \%$ range for their country), not very well off (within the $25 \%$ to $50 \%$ range from "country"), or quite poor (within the lowest $25 \%$ in their country, in terms of wealth) (Wardle and Steptoe, 1991).

\section{Data analysis}

The data were analysed using IBM SPSS (version 20.0). The proportion of BSE knowledge, practice and attitude were calculated as a percentage and means and standard deviations, respectively. Logistic regression analysis was done with STATA to calculate the crude odds ratio (OR) with $95 \%$ confidence interval (CI) to determine the associations between BSE attitude and BSE practice (any practice coded as 1 , and no practice coded as 0 ) and age was adjusted for. The country was entered as the primary sampling unit for survey analysis in order to achieve accurate CIs, given the clustered nature of the data.

\section{Results}

\section{Cervical cancer screening practice and attitude}

The final sample included 9194 female undergraduate university students aged 18-26 years (mean age 20.9, $\mathrm{SD}=2.0$ ). Overall, $11.6 \%$ of the female students indicated that they had conducted one or more times a cervical (Pap) smear test; this was $8.3 \%$ among 18-20 yearolds and $15.6 \%$ among 21-26 year-old students. There was considerable country variation on having had a cervical (Pap) smear test, among 21-26 year-old female university students, ranging from $59.2 \%$ in Colombia and $50.9 \%$ in Barbados to $0 \%$ in India and $1.0 \%$ in Tunesia. Female students, aged 21-26 years, from a large group of participating countries (Southeast Asian countries, India, Pakistan, China, Tunesia, Turkey, Cameroon, Ivory Coast, Madagascar, Mauritius) reported having had less than $10 \%$ a cervical (Pap) smear test, while a number of participating countries reported rates above $20 \%$ including countries in the Caribbean and South America, Namibia, Nigeria and South Africa, and Russia.

On a scale from 1-10 (10 being the most important), female students rated the importance of having a regular cervical (Pap) smear test as an average of 7.2. There was also a considerable variation in the ratings of the importance of having a regular cervical (Pap) smear test ranging from below a mean of 6.0 in Madagascar, Nigeria, Turkey and India to a mean of above 8 in Colombia, Ivory 
Table 1. Cervical Cancer Screening Practice and Attitude by Country

\begin{tabular}{|c|c|c|c|c|c|c|c|}
\hline \multirow[t]{3}{*}{ Country } & & \multirow{3}{*}{$\begin{array}{c}\text { Sample } \\
\text { No. }\end{array}$} & \multicolumn{3}{|c|}{ Had cervical (Pap) smear test (years) } & \multirow{3}{*}{$\begin{array}{c}\text { Cervical (Pap) smear test } \\
\text { Importance (range 1-10) } \\
\text { M (SD) }\end{array}$} & \multirow{3}{*}{$\begin{array}{c}\text { Attitude-Practice } \\
\text { Statistic }\end{array}$} \\
\hline & & & $18-26$ & $18-20$ & $21-26$ & & \\
\hline & & & $\%$ & $\%$ & $\%$ & & \\
\hline All & & 9194 & 11.6 & 8.3 & 15.6 & $7.2(3.1)$ & $<0.001$ \\
\hline \multirow{5}{*}{ Caribbean and South America } & Barbados & 221 & 31.7 & 11.2 & 50.9 & $7.6(2.7)$ & $<0.001$ \\
\hline & Grenada & 216 & 28.2 & 8.9 & 39.4 & $7.8(2.6)$ & $<0.001$ \\
\hline & Jamaica & 514 & 11.3 & 6.4 & 24.6 & $7.2(3.0)$ & $<0.001$ \\
\hline & Colombia & 451 & 38.1 & 22 & 59.2 & $8.2(2.7)$ & $<0.001$ \\
\hline & Venezuela & 275 & 22.9 & 12.1 & 34.1 & $6.3(3.3)$ & $<0.001$ \\
\hline \multirow[t]{7}{*}{ Sub-Saharan Africa } & Cameroon & 351 & 2.8 & 2.2 & 3.3 & $7.5(2.7)$ & 0.389 \\
\hline & Ivory Coast & 338 & 4.3 & 3.9 & 4.9 & $8.1(3.7)$ & 0.443 \\
\hline & Madagascar & 323 & 2.8 & 2.4 & 4.3 & $5.1(3.3)$ & 0.143 \\
\hline & Mauritius & 314 & 3.2 & 4.8 & 1.8 & $7.4(2.7)$ & 0.121 \\
\hline & Namibia & 257 & 24.1 & 10.3 & 34 & $7.7(2.8)$ & $<0.001$ \\
\hline & Nigeria & 244 & 31.1 & 33 & 30 & $5.1(3.9)$ & $<0.001$ \\
\hline & South Africa & 345 & 19.1 & 15.4 & 21.9 & $7.5(3.1)$ & 0.214 \\
\hline \multirow[t]{4}{*}{ North Africa and Central Asia } & Tunesia & 347 & 1.7 & 2.6 & 1 & $6.7(3.5)$ & 0.712 \\
\hline & Turkey & 377 & 4.2 & 4 & 4.7 & $5.3(3.8)$ & 0.075 \\
\hline & Russia & 368 & 34.2 & 33.8 & 35.3 & $7.1(2.8)$ & 0.108 \\
\hline & Kyrgyzstan & 475 & 14.3 & 11 & 15.6 & $8.0(2.7)$ & 0.483 \\
\hline \multirow[t]{4}{*}{ South Asia and China } & Bangladesh & 256 & 11.7 & 11.4 & 12.1 & $6.4(3.1)$ & 0.037 \\
\hline & India & 259 & 7.1 & 7.1 & $0.0^{*}$ & $5.7(3.9)$ & 0.101 \\
\hline & Pakistan & 457 & 2.4 & 2.2 & 3.3 & $9.1(1.2)$ & 0.54 \\
\hline & China & 636 & 4.7 & 3.7 & 7.1 & $6.9(2.1)$ & 0.04 \\
\hline \multirow[t]{5}{*}{ Southeast Asia } & Indonesia & 305 & 2.3 & 1.5 & 3.7 & $8.5(2.8)$ & 0.164 \\
\hline & Laos & 528 & 4.2 & 8.7 & 3.5 & $7.7(3.2)$ & 0.002 \\
\hline & Philippines & 385 & 3.6 & 3.6 & 4 & $6.9(2.6)$ & 0.541 \\
\hline & Singapore & 414 & 5.8 & 6.7 & 4.9 & $6.4(2.4)$ & 0.08 \\
\hline & Thailand & 599 & 4.2 & 2.2 & 7.1 & $7.6(2.6)$ & 0.242 \\
\hline
\end{tabular}

Table 2. Relationship between Sociodemographics, Cancer Risk Behaviour and Cervical Cancer Screening Practice

\begin{tabular}{|c|c|c|c|c|}
\hline Variables & & $\begin{array}{l}\text { Practice } \\
\text { No. }(\%)\end{array}$ & $\begin{array}{l}\text { Unadjusted Odds Ratio } \\
\qquad(95 \% \mathrm{CI})\end{array}$ & $\begin{array}{l}\text { Adjusted Odds Ratio } \\
(95 \% \mathrm{CI})\end{array}$ \\
\hline \multirow[t]{2}{*}{ Marital status } & Single $(n=8338)$ & $978(11.0)$ & 1 & 1 \\
\hline & Married $(n=361)$ & $159(38.5)$ & $4.13(3.27-5.22) * * *$ & $3.20(2.50-4.09)^{* * *}$ \\
\hline \multirow[t]{4}{*}{ Economic family background } & Wealthy $(n=360)$ & $57(14.6)$ & 1 & 1 \\
\hline & Quite well off $(n=4574)$ & $540(12.1)$ & $0.73(0.54-0.99)^{*}$ & $0.88(0.60-1.31)$ \\
\hline & Not well off $(n=3611)$ & $414(11.3)$ & $0.63(0.46-0.86)^{* *}$ & $0.93(0.62-1.37)$ \\
\hline & Poor $(n=642)$ & $102(16.0)$ & $1.00(0.701 .44)$ & $1.19(0.76-1.87)$ \\
\hline \multirow[t]{2}{*}{ Sexual activity in the past 12 months } & Not sexually active $(n=5808)$ & $414(6.6)$ & 1 & 1 \\
\hline & Sexually active $(n=3173)$ & 718 (23.9) & $4.06(3.55-4.64) * * *$ & $3.62(2.98-4.39) * * *$ \\
\hline \multirow[t]{2}{*}{ Number of sexual partners in the past 12 months } & $0-1(n=7821)$ & $902(10.9)$ & 1 & 1 \\
\hline & 2 or more $(n=1140)$ & $188(26.7)$ & $3.15(2.61-3.80) * * *$ & $1.60(1.30-1.99)^{* * *}$ \\
\hline \multirow[t]{2}{*}{ Condom use in the past 3 months } & Consistent $(n=765)$ & $198(23.7)$ & 1 & 1 \\
\hline & Inconsistent $(\mathrm{n}=2485)$ & $512(15.6)$ & $0.67(0.56-0.80)^{* * *}$ & $0.79(0.65-0.96)^{*}$ \\
\hline \multirow[t]{2}{*}{ Sexually transmitted infection } & Never $(n=8502)$ & $1073(12.2)$ & 1 & 1 \\
\hline & Ever $(n=415)$ & $107(19.7)$ & $2.49(1.95-3.17) * * *$ & $1.16(0.89-1.49)$ \\
\hline \multirow[t]{2}{*}{ Current tobacco use } & No $(n=8377)$ & $987(11.5)$ & 1 & 1 \\
\hline & Yes $(n=612)$ & $102(17.0)$ & $1.66(1.32-2.08) * * *$ & $1.34(1.03-1.75)^{*}$ \\
\hline \multirow[t]{2}{*}{ Benefits of cervical cancer screening rating } & $1-7(n=3842)$ & $342(9.5)$ & 1 & 1 \\
\hline & $8-10(n=5341)$ & $801(14.8)$ & $1.56(1.36-1.79) * * *$ & $1.83(1.53-2.20)^{* * *}$ \\
\hline
\end{tabular}

Coast, Pakistan and Indonesia. The predictive value of attitudes towards cervical cancer screening was evaluated by logistic regression with age as a control variable for each country. For this analysis, cervical cancer screening was coded as never (0) or ever (1), and only p-values are reported. Overall, and in nine countries a positive relationship between cervical cancer screening attitude and practice was found (Table 1).

Cervical cancer risk behaviour and cervical cancer screening practice

Logistic regression analyses found that the cancer risk behaviours of being sexually active, having multiple sexual partners, consistent condom use, current tobacco use and high importance of cervical cancer screening were found to be associated with the prevalence cervical cancer screening practice (Table 2).

\section{Discussion}

The study found, among a large sample of female university students across 25 low and middle and emerging economy countries, an overall low participation rate in cervical cancer screening, which is comparable to previous studies in low and middle income countries

(Ayinde et al., 2004; Akujobi et al., 2008; Oladepo et al., 2008; 2009; Abotchie and Shokar, 2009; Al-Naggar et al., 2010; Aniebue and Aniebue, 2010; Hoque, 2013; 
Dhendup and Tshering, 2014). In particular because of the high burden cervical cancer in low and middle income countries, more should be done to promote cervical cancer screening in this population. This is especially important in those countries participating in this study with a very low participation rate (0-7.1\%) among 21-26 year-old students from Southeast Asian countries, India, Pakistan, China, Tunesia, Turkey, Cameroon, Ivory Coast, Madagascar, and Mauritius. Country variations in the prevalence of cervical cancer screening may be due to various country specific factors, including cervical cancer screening policy, publicity on cervical cancer, systematic and active promotion of screening, accessibility of cancer screening services, and social-and cultural factors specific to the Asian population (Lu et al., 2012; Dhendup and Tshering, 2014).

Further, the study found that women who rated cervical cancer screening as more important carried it out more often. This finding is in agreement with previous studies (Akujobi et al., 2008; Abotchie and Shokar, 2009; Aniebue and Aniebue, 2010; Oshima and Maezawa, 2013). However, in particular in female university students from Ivory Coast, Indonesia and Pakistan, who gave a high rating of cervical cancer screening importance (mean score above 8), fewer than 5\% reported cervical cancer screening practice. It appears factors other than the importance evaluations are relevant in establishing a cervical cancer screening practice. For example, women in this younger age group may believe that cervical cancer screening is important in general but only at an older age. In a number of participating study countries the recommended beginning of cervical cancer screening was 25 years. An interesting finding was that sexual risk behaviour and tobacco use, being cervical cancer risk factors, were associated with cervical cancer screening. This finding may have implications for cervical cancer screening programmes.

Study limitations: This study had several limitations. The study was cross-sectional, so causal conclusions cannot be drawn. The investigation was carried out with students from one or two universities in each country, and inclusion of other centres could have resulted in different results. University students are not representative of young adults in general, and the cervical cancer screening attitude and practice may be different in other sectors of the population. Future studies of this nature should include knowledge, attitude and practice of Human Papillomavirus (HPV), the main cause of cervical cancer, vaccination (Ghojazadeh et al., 2012; Rashwan et al., 2012; Hoque and Ghuman, 2013).

In conclusion, results show that cervical cancer screening practices among this large sample of female undergraduate university students was inadequate. Efforts should be made to develop educational programmes that can increase the importance related to cervical cancer as well as the practice of cervical cancer screening.

\section{Acknowledgements}

Partial funding for this study was provided by the South African Department of Higher Education. The following colleagues participated in this student health survey and contributed to data collection (locations of universities in parentheses) Bangladesh: Gias Uddin Ahsan (Dhaka); Barbados: T. Alafia Samuels (Bridgetown); China: Tony Yung and Xiaoyan Xu (Hong Kong and Chengdu); Cameroon: Jacques Philippe Tsala Tsala (Yaounde); Colombia: Carolina Mantilla (Pamplona); Grenada: Omowale Amuleru-Marshall (St. George); India: Krishna Mohan (Visakhapatnam); Indonesia: Indri Hapsari Susilowati (Jakarta); Ivory Coast: Issaka Tiembre (Abidjan); Jamaica: Caryl James (Kingston); Kyrgyzstan: Erkin M Mirrakhimov (Bishkek); Laos: Vanphanom Sychareun (Vientiane); Madagascar: Onya H Rahamefy (Antananarivo); Mauritius: Hemant Kumar Kassean (Reduit, Moka); Namibia: Pempelani Mufune (Windhoek); Nigeria: Solu Olowu (Ile-Ife); Pakistan: Rehana Reman (Karachi); Philippines: Alice Ferrer (Miagao); Russia: Alexander Gasparishvili (Moscow); Singapore: Mee Lian Wong (Singapore); South Africa: Tholene Sodi (Polokwane); Thailand: Tawatchai Apidechkul (Chiang Rai); Tunisia: Hajer AounallahSkhiri (Tunis); Turkey: Neslihan Keser Ozcan (Istanbul); Venezuela: Yajaira M Bastardo (Caracas).

\section{References}

Abotchie PN, Shokar NK (2009). Cervical cancer screening among college students in Ghana: knowledge and health beliefs. Int J Gynecol Cancer, 19, 412-6.

Akujobi CN, Ikechebelu JI, Onunkwo I, Onyiaorah IV (2008). Knowledge, attitude and practice of screening for cervical cancer among female students of a tertiary institution in South Eastern Nigeria. Niger J Clin Pract, 11, 216-9.

Al-Naggar RA, Low WY, Isa ZM (2010). Knowledge and barriers towards cervical cancer screening among young women in Malaysia. Asian Pac J Cancer Prev, 11, 867-73.

Aniebue PN, Aniebue UU (2010). Awareness and practice of cervical cancer screening among female undergraduate students in a Nigerian university. J Cancer Educ, 25, 106-8.

Ayinde OA, Omigbodun AO, Ilesanmi AO (2004). Awareness of cervical cancer, papanicolaou's smear and its utilisation among female undergraduates in Ibadan. Afr J Reprod Hlth, 8, 68-80.

Bakogianni GD, Goutsou SC, Liti MV, et al (2012). Knowledge, attitude, and practice of cervical cancer screening among Greek students: a short report. Int J Adolesc Med Health, 24, 329-30.

Botha H, Cooreman B, Dreyer G, et al (2010). Cervical cancer and human papillomavirus: South African guidelines for screening and testing. South Afr J Gynaecol Oncol, 2, 23-26.

Chou P (1991). Review on risk factors of cervical cancer. Zhonghua Yi Xue Za Zhi, 48, 81-8.

Dhendup T, Tshering P (2014). Cervical cancer knowledge and screening behaviors among female university graduates of year 2012 attending national graduate orientation program, Bhutan. BMC Womens Health, 14, 44.

Durvasula RS, Regan PC, Ureño O, Howell L (2006). Frequency of cervical and breast cancer screening rates in a multi-ethnic female college sample. Psychol Rep, 99, 418-20.

Ghojazadeh M, Azar ZF, Saleh P, Naghavi-Behzad M, Azar NG (2012). Knowledge and attitude of Iranian University students toward human papilloma virus. Asian Pac J Cancer Prev, 13, 6115-9.

Ghotbi N, Anai A (2012). Assessment of the knowledge and attitude of female students towards cervical cancer 

prevention at an international university in Japan. Asian Pac J Cancer Prev, 13, 897-900.

Globocan (2012). Estimated cancer incidence, mortality and prevalence worldwide in 2012. Available at: http://globocan. iarc.fr/Default.aspx, accessed 25 May 14.

Hoque ME (2013). Awareness of cervical cancer, Papanicolau's smear and its utilization among female, final year undergraduates in Durban, South Africa. J Cancer Res Ther, 9, 25-8.

Hoque ME, Ghuman S, Hal GV (2013). Human papillomavirus vaccination acceptability among female university students in South Africa. Asian Pac J Cancer Prev, 14, 4865-9.

Lu M, Moritz S, Lorenzetti D, et al (2012). A systematic review of interventions to increase breast and cervical cancer screening uptake among Asian women. BMC Public Health, 12, 413 .

Murthy NS, Mathew A (2000). Risk factors for pre-cancerous lesions of the cervix. Eur J Cancer Prev, 9, 5-14.

Oladepo O, Ricketts OL, John-Akinola Y (2008/9). Knowledge and utilization of cervical cancer screening services among Nigerian students. Int $Q$ Community Health Educ, $\mathbf{2 9}$, 293-304.

Oshima S, Maezawa M (2013). Perception of cervical cancer screening among Japanese university students who have never had a pap smear: a qualitative study. Asian Pac $J$ Cancer Prev, 14, 4313-8.

Pan American Health Organization (2013). Situational analysis of cervical cancer prevention and control in the Caribbean: Results from a 2013 assessment of country policies and services for HPV vaccination, cervical cancer screening, diagnosis and treatment.

Peirson L, Fitzpatrick-Lewis D, Ciliska D, Warren R (2013). Screening for cervical cancer: a systematic review and metaanalysis. Syst Rev, 2, 35 .

Rashwan HH, Saat NZ, Abd Manan DN (2012). Knowledge, attitude and practice of Malaysian medical and pharmacy students towards human papillomavirus vaccination. Asian Pac J Cancer Prev, 13, 2279-83.

The United States Preventive Services Task Force (USPSTF, 2012). Screening for Cervical Cancer: Clinical Summary of U.S. Preventive Services Task Force Recommendation. AHRQ Publication No. 11-05156-EF-3, March 2012. Available at: http://www.uspreventiveservicestaskforce.org/ uspstf11/cervcancer/cervcancersum.htm.

Wardle J, Steptoe A (1991). The European Health and Behaviour Survey: rationale, methods and initial results from the United Kingdom. Soc Sci Med, 33, 925-36.

World Health Organization (WHO) (2008). Guidelines for controlling and monitoring the tobacco epidemic. Geneva: WHO.

World Health Organization (WHO) (2013). WHO guidelines for screening and treatment of precancerous lesions for cervical cancer prevention. Geneva, Switzerland: WHO. 